Original Research Article

\title{
Prevalence of obesity and prediabetes in above 40 years age group based on glycated hemoglobin levels among health care professional in Patna, India
}

\author{
Amrendra Prasad Singh*
}

Department of Geriatrics, Patna Medical College and Hospital, Patna, Bihar, India

Received: 23 January 2019 Accepted: 07 February 2019

\section{*Correspondence to:}

Dr. Amrendra Prasad Singh, Email: amrendrapdsingh@ yahoo.co.in

Copyright: (C) the author(s), publisher and licensee Medip Academy. This is an openaccess article distributed under the terms of the Creative Commons Attribution NonCommercial License, which permits unrestricted noncommercial use, distribution, and reproduction in any medium, provided the original work is properly cited.

\begin{abstract}
Background: This study aimed to assess the prevalence of prediabetes using glycated hemoglobin (HbA1c) in above 40 years age group health care professional in Patna.

Methods: This was a cross sectional study carried out amongst 315 employees of the Independent Public Central Hospital in Patna. The selection of healthcare professionals for the study was random. The largest study subgroup $(63.4 \%)$ were nurses, followed by word attender (13.5\%), other administrative employee $(10.3 \%)$, and orderlies (6.6\%). All subjects underwent glycated hemoglobin level measurement at hospital laboratory. Data were analysed using descriptive statistics, chi-square and binary logistic regression tests at value of $\mathrm{p}<0.05$.

Results: The study group was evaluated for prediabetes (expressed in the form of HbA1c levels) with an American Diabetes Association-approved classification. The results indicated that a vast majority of the evaluated healthcare personnel (383 people; $82.4 \%$ ) had normal glycated hemoglobin levels. The remainder of the study group showed carbohydrate metabolism disturbances. The range of glycated hemoglobin levels $(5.7-6.4 \%)$ found in 73 people $(15.7 \%)$ suggested an increased risk for diabetes. As a result of the study, as few, or as many, as 9 people $(1.9 \%)$ were diagnosed with diabetes (initial diagnosis).

Conclusions: These results emphasize the need to develop an urgent public program to improve the detection, prevention, and treatment of diabetes. Most of the evaluated healthcare professionals $(79.36 \%)$ showed no evidence of being at risk for type 2 diabetes mellitus. Only $17.6 \%$ of respondents were unaware of their metabolic disturbances. The study demonstrated a positive correlation between body mass index values and glycated hemoglobin levels in the evaluated group of healthcare professionals $(\mathrm{R}=0.3)$, which was similar to that found in the general population.
\end{abstract}

Keywords: BMI, Healthcare, HbA1c, Obesity, Prediabetes

\section{INTRODUCTION}

Type 2 diabetes is recognized as a global health problem nowadays, and it has been projected that the number of diabetic patients will rise from an estimated 135 million in 1995 to 300 million in $2025 .{ }^{1}$. Moreover, the Asia-Pacific region is considered to be on the verge of an emerging diabetes epidemic. ${ }^{2}$ Glycemic control is fundamental to the management of diabetes. ${ }^{3}$ Prospective randomized clinical trials have shown that achieving glycemic control is associated with decreased rates of retinopathy, nephropathy, and neuropathy, and epidemiological studies support the potential of intensive glycemic control in the reduction of cardiovascular disease. ${ }^{4}$

Individuals with diabetes have a higher risk of complications such as retinopathy, nephropathy, neuropathy, and cardiovascular disease..$^{5}$ According to the Korea National Statistical Office, the mortality rate due to diabetes was 25.0 per 100,000 persons in 2003 , and thus it 
is currently rated as Korea's fourth leading cause of death. ${ }^{6}$ Although the importance of early diagnosis and secondary intervention programs for the prevention of diabetes complications have been emphasized, about one-half of those with diabetes remain unidentified. ${ }^{7}$ Epidemiological studies on diabetes have a significant impact on diabetes research, care, and prevention programs.

Important element of diabetes prevention, especially T2DM, is health-oriented education of the general public. However, considering the extent of the need for public education in this field, the help of other healthcare professionals, who are also able to initiate preventive measures and detect the first signs and symptoms of carbohydrate metabolism disturbances, must be sought.

In this study, we analysed the prevalence of prediabetes using glycated hemoglobin (HbA1c) in above 40 years age group health care professional in Patna, India.

\section{METHODS}

This was a cross sectional study carried out amongst 315 employees of the Independent Public Central Hospital in Patna. The selection of healthcare professionals for the study was random. Each subject had to meet the inclusion criteria which was being a healthcare professional employed at hospital in Patna; having no awareness of suffering from T2DM. The largest study subgroup (63.4\%) were nurses, followed by word attender $(13.9 \%)$, other administrative employee (10.16\%), and orderlies (12.5\%).
All subjects underwent glycated hemoglobin level measurement at hospital laboratory. All subjects completed a questionnaire on their anthropometric data (weight, height) and information on their medical profession. Only fully and correctly completed questionnaires were included in the analysis. The findings served as the basis for assessing the risk of diabetes.

\section{Statistical analysis}

Information collected was recorded in a Master Chart. Data analysis was done with the help of computer using Epidemiological Information Package (EPI 2010) developed by Centre for Disease Control, Atlanta, Graph pad prism 6 and Microsoft excel. Using this software range, frequency, percentage, mean, standard deviation, chi square and ' $p$ ' values were calculated. Kruskul Wallis chi-square test was used to find the significant difference between quantitative variables and Yate's chi square test for qualitative variables. A ' $p$ ' value less than 0.05 is taken to denote significant relationship.

\section{RESULTS}

The mean age in the study group was $45.6 \pm 5.3$ years. The differences between the first quartile and minimum values and between the maximum and third quartile values were 10 and 24, respectively. This demonstrated the age distribution to be skewed to the right. The mean age was lower than the median, which meant that more than a half of subjects were at an age above the mean value (Table 1).

Table 1: Mean age, BMI and HbA1c in participants.

\begin{tabular}{|c|c|c|c|c|c|c|c|c|}
\hline \multirow{2}{*}{ Variable } & \multicolumn{2}{|c|}{ Nurse group (n=200) } & \multicolumn{2}{|c|}{$\begin{array}{l}\text { Word attender group } \\
(\mathrm{n}=\mathbf{4 4 )}\end{array}$} & \multicolumn{2}{|c|}{$\begin{array}{l}\text { Other medical } \\
\text { personnel }(n=32)\end{array}$} & \multicolumn{2}{|c|}{$\begin{array}{l}\text { Hospital orderlies } \\
(\mathbf{n}=\mathbf{3 9})\end{array}$} \\
\hline & Mean \pm SD* & Range & Mean \pm SD* & Range & Mean \pm SD* & Range & Mean \pm SD* & Range \\
\hline Age (yr) & $47.7 \pm 5.2$ & $40-62$ & $45.2 \pm 5.1$ & $41-65$ & $44.8 \pm 4.2$ & $40.0-60.0$ & $44.6 \pm 4.2$ & $41.0-58.0$ \\
\hline $\begin{array}{l}\mathrm{BMI} \\
\left(\mathrm{Kg} / \mathrm{m}^{2}\right)\end{array}$ & $25.2 \pm 2.4$ & $20.3-33.3$ & $24.3 \pm 3.8$ & $17.2-33.06$ & $25.6 \pm 4.6$ & $17.6-44.2$ & $26.2 \pm 5.3$ & $16.7-38.9$ \\
\hline HbAlc (\%) & $5.4 \pm 0.3$ & $4.8-6.5$ & $5.5 \pm 0.9$ & $4.6-9.6$ & $5.4 \pm 0.5$ & $4.1-9.0$ & $5.4 \pm 0.3$ & $4.9-6.0$ \\
\hline
\end{tabular}

The body mass index (BMI) was also evaluated. Twelve respondents, which constituted $3.8 \%$ of all the randomly selected healthcare professionals undergoing evaluation, were underweight.

A total of 159 subjects $(50.5 \%)$ exhibited normal body weight (within normal limits), 101 (32.06\%) were overweight, and $56(17.8 \%)$ were obese. The minimum BMI value in the study group was $16.7 \mathrm{~kg} / \mathrm{m}^{2}$, and the maximum $44.2 \mathrm{~kg} / \mathrm{m}^{2}$ (mean $25.4 \pm 4.5 \mathrm{~kg} / \mathrm{m}^{2}$, median $24.6 \mathrm{~kg} / \mathrm{m}^{2}$ ). The first and third quartile BMI values were $22.2 \mathrm{~kg} / \mathrm{m}^{2}$ and $27.7 \mathrm{~kg} / \mathrm{m}^{2}$, respectively (Table 1 ).
The maximum, mean, and minimum HbA1c levels in the evaluated healthcare professionals were $9.6 \%, 5.4 \%$, and $4.1 \%$ respectively. The median and mean values differed only by $0.1 \%$. Quartile values and their respective extremes were: 1 for the minimum and 4 for the maximum, which indicated a right skewed distribution. HbA1c levels showed a lesser variance than other analysed parameters.

\section{DISCUSSION}

The delay in diagnosing T2DM is a significant problem of modern medicine. T2DM may be asymptomatic for many 
years. Therefore, it is often detected incidentally during routine diagnostic evaluations. ${ }^{8}$ Considering the high cost of treatment, which is mostly due to diabetic complications, it seems necessary to introduce preventive programs. ${ }^{9}$ Both the prevalence and incidence of type 2 diabetes are increasing worldwide in conjunction with increased Westernization of the population's lifestyle. ${ }^{10}$ The risk for microvascular complications is related to overall glycemic burden over time as measured by A1C. ${ }^{11,12}$

The main aim of this study was to assess the risk of T2DM in different professions by analysing randomly selected healthcare professionals employed at hospital in Patna. The study group evaluated in terms of two parameters: the rates of metabolic disturbances (expressed in terms of HbA1c levels) and body weight abnormalities as one of the key risk factors for T2DM. The first parameter was evaluated via a diabetes screening test based on assessing glycated hemoglobin at hospital laboratory. The results were analysed according to ADA's criteria. The adopted cut-off HbAlc level indicating diabetes was $\geq 6.5 \%$, whereas HbA1c levels of 5.7-6.4\% marked a high risk of diabetes. A vast majority of subjects $250(79.36 \%)$ had normal HbA1c levels. High risk of diabetes was detected in 58 subjects $(18.4 \%)$, while only $7(2.2 \%)$ of subjects met diagnostic criteria for diabetes. Comparing the results demonstrated by the evaluated healthcare professionals with those shown as part of a multicentre trial in the Polish population, we can see significant differences.

The results of our study indicated a need for active efforts to identify people with prediabetes or undiagnosed diabetes. The study also emphasized the problem of overweight and obesity (which requires instituting appropriate behavioural management), present also among healthcare professionals.

\section{CONCLUSION}

Most of the evaluated healthcare professionals demonstrated a good knowledge of the signs and symptoms of T2DM. Only $17.6 \%$ of respondents were unaware of their metabolic disturbances. Slightly over half $(50.5 \%)$ of the study group had normal BMI values, which does not give much credit to the preventive awareness in the evaluated healthcare group.

Funding: No funding sources

Conflict of interest: None declared

Ethical approval: The study was approved by the Institutional Ethics Committee

\section{REFERENCES}

1. King H, Aubert RE, Herman WH. Global burden of diabetes, 1995-2025: prevalence, numerical estimates, and projections. Diab Care. 1998 Sep 1;21(9):1414-31.

2. Amos AF, McCarty DJ, Zimmet P. The rising global burden of diabetes and its complications: estimates and projections to the year 2010. Diab Med. 1997 Dec;14(S5):S7-85.

3. Tuomilehto J, Lindström J, Eriksson JG, Valle TT, Hämäläinen H, Ilanne-Parikka P, et al. Prevention of type 2 diabetes mellitus by changes in lifestyle among subjects with impaired glucose tolerance. New Eng J Med. 2001 May 3;344(18):1343-50.

4. Schlienger JL, Type 2 diabetes complications. Presse Med. 2013 May;42(5):839-48.

5. American Diabetes Association: Standards of medical care for patients with diabetes mellitus (Position Statement). Diab Care. 2003 Jan;26 Suppl 1:S33-50.

6. Statistical Results About Cause of Death. 2003. Daejeon, Korea, National Statistical Office, 2004.

7. Roman SH, Harris MI. Management of diabetes mellitus from a public health perspective. Endocrinol Metab Clin. 1997 Sep 1;26(3):443-74.

8. Strojek K, Potyralska MM. Evaluation of the usefulness of HbAlc measurement for diagnosing diabetes in a selected sample of the Polish population. Clin Diabetol. 2014;3(2):51-6.

9. Czech A. Urgent need for prevention in the practice of sociomedical care for people with type 2 diabetes world and Poland. Metab Med. 2010;14:10-5.

10. Raz I. Guideline approach to therapy in patients with newly diagnosed type 2 diabetes. Diabetes Care. 2013;36 (Suppl 2):S139-44.

11. UK Prospective Diabetes Study (UKPDS) Group. Intensive blood-glucose control with sulphonylureas or insulin compared with conventional treatment and risk of complications in patients with type 2 diabetes (UKPDS 33). Lancet. 1998 Sep 12;352(9131):837-53.

12. UK Prospective Diabetes Study (UKPDS) Group Effect of intensive blood-glucose control with metformin on complications in overweight patients with type 2 diabetes (UKPDS 34). Lancet. 1998;352:854-65.

Cite this article as: Singh AP. Prevalence of obesity and prediabetes in above 40 years age group based on glycated hemoglobin levels among health care professional in Patna, India. Int J Basic Clin Pharmacol 2019;8:601-3. 